\title{
Chronic Diseases as a Risk Factor for Frailty Syndrome
}

\author{
Moreno-Sanchez MM', Martínez-Castillo J A ${ }^{1}$, \\ García-Leija DL ${ }^{1}$, Ramirez-Gonzalez J F' ${ }^{1}$ Diaz- \\ Alfaro $\mathrm{JA}^{2}$ and Ramirez-Leyva $\mathrm{DH}^{3 *}$ \\ ${ }^{1}$ Department of Family Medicine, Family Medicine Unit \\ \#32 (IMSS), Nuevo Leon Delegation, Mexico \\ ${ }^{2}$ Department of Family Medicine, General Hospital Zone \\ \#1 (IMSS), Durango Delegation, Mexico \\ ${ }^{3}$ Department of Family Medicine, Family Medicine Unit \\ \#37 (IMSS), Sinaloa Delegation, Mexico \\ *Correspondling author: Ramirez-Leyva Diego \\ Hazael, Department of Family Medicine, Family Medicine \\ Unit \#37 (IMSS), Sinaloa Delegation, México
}

Received: J anuary 08, 2019; Accepted: February 08, 2019; Published: February 15, 2019

\section{Abstract}

Background: Among the factors that favor the frailty of the elderly are chronic diseases and the existence of comorbidities, which increase the prevalence of disability and mortality, the prevalence of frailty in Mexico is around $39 \%$.

Aim: The purpose of this study is to determine the association between frailty and risk factors in older adults in Guadalupe, Nuevo Leon.

Design and Setting: Comparative cross-sectional study.

Methods: A comparative cross-sectional study was conducted, using a nonprobabilistic sampling for consecutive cases in a period of time from January 2016 to January 2018. The Ensurd criteria were applied to assess the presence of frailty among the participants and to make an association between the following variables: sex, diabetes mellitus, arterial hypertension, osteoporosis and polypharmacy. For statistical analysis, association was established with odds ratio and chi-squared test for statistical significance, it was used $95 \%$ interval confidence $(p<0.05)$.

Results: 197 medical records were evaluated, 19 were excluded due to incomplete records. 181 records were included for the study, obtaining 105 cases (58.01\%) and 76 controls (41.99\%). When making an association between frailty and the variables collected, the following significant results were found: Sex (OR 1.04, 95\% Cl 0.55-1.97, p >0.05), osteoporosis (OR 1.41, 95\% $\mathrm{Cl} 0.25-7.93, p>0.05$ ), diabetes mellitus (OR $0.68,95 \% \mathrm{Cl} 0.35-1.26, p>0.05$ ), arterial hypertension (OR $1.16,95 \% \mathrm{Cl} 0.61-2.18, \mathrm{p}>0.05)$ and polypharmacy (OR $1.5,95 \% \mathrm{Cl} 0.80-2.8, \mathrm{p}>0.05)$. None of the associations was statistically significant.

Conclusion: The undoubted existence of frailty syndrome and considering frailty as a geriatric syndrome is necessary to have accurate and current information on the risk factors associated with the frailty syndrome that influence the prognosis in the frail patient.

Keywords: Frailty Syndrome; Older Adults; Ensurd Criteria; Chronic Diseases

\section{Introduction}

The demographic and epidemiological transition associated with the increase in life expectancy has had important implications for health systems throughout the world, the main change detected is population aging. In Mexico, by the year 2030 the percentage of the aging population will rise to $14.9 \%$ [1]. Between 2005 and 2050 the population of older adults will increase around 26 million although more than $75 \%$ of this increase will occur after 2020 . This phenomenon generates an increase in diseases associated with age, among them fragility, which is considered a geriatric syndrome [2]. Fragility is defined as a syndrome of physiological deterioration in old age, characterized by a strong vulnerability to adverse health outcomes. Fragile older adults are less able to adapt to stressors such as acute illness or trauma [3].

Fragility is associated with poor health outcomes, hospitalization and death. In Latin America, the prevalence of frailty is $30-48 \%$ in women and $21-35 \%$ in men; in Mexico, it is $39 \%$, and it is more frequent in women $(45 \%)$ than in men $(30 \%)$. There is an increase in the prevalence of frailty among those with the highest number of comorbidities. The quantification of fragility is particularly important, since it provides us valuable information about the risk of dependence or death in old patients [4]. The frail patient is one who is delicate in health, weak and not vigorous or robust. It is a syndrome that carries a high risk of mortality, disability, institutionalization, hospitalizations, falls, fractures, postoperative complications, poor health and even venous thromboembolism [5]. It is recommended to use the proposal of Ensrud and collaborators to detect frailty syndrome, which consists of assessing 3 criteria: loss of weight of 5\% regardless of whether it was intentionally or not in the last 3 years, inability to get up from a chair five times without using the arms, reduced energy level using the question: Do you feel full of energy? Considering a $\mathrm{NO}$, as a response for 1 point. Its interpretation is as follows: 0 points $=$ Sturdy patient, 1 point $=$ pre-frail patient, 2 or 3 points= fragile patient [5].

Among the medical risk factors for development of frailty are: coronary heart disease, chronic obstructive pulmonary disease, cerebral vascular disease, congestive heart failure, diabetes mellitus,
J Fam Med - Volume 6 Issue 1 - 2019

ISSN : 2380-0658 | www.austinpublishing group.com

Ramirez-Leyva et al. (C) All rights are reserved
Citation: Moreno-Sanchez MM, Martínez-Castillo JA, García-Leija DL, Ramirez-Gonzalez JF, Diaz-Alfaro JA and Ramirez-Leyva DH. Chronic Diseases as a Risk Factor for Frailty Syndrome. J Fam Med. 2019; 6(1): 1159. 


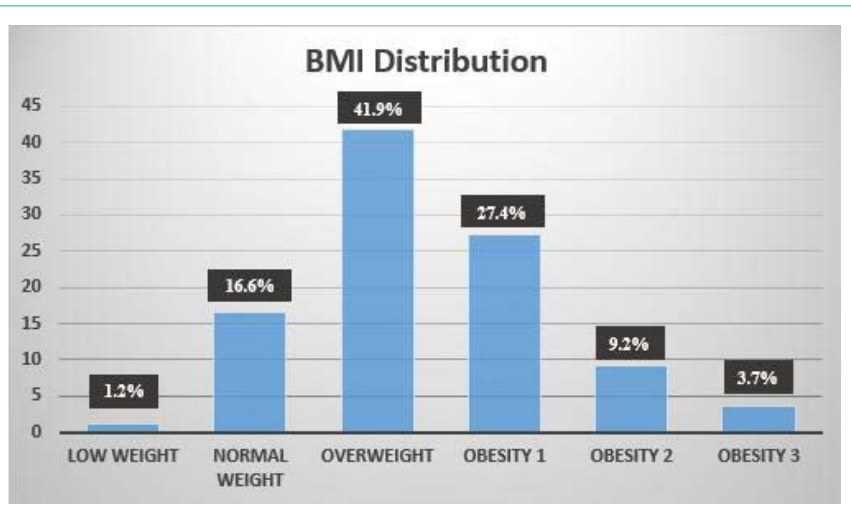

Graphic 1: Descriptive analysis of the distribution by body mass index (BMI).

hypertension, arthritis, anemia, depression, smoking, use of hormone replacement therapy, polypharmacy and vitamin D deficiency [5]. The factors that have a worse prognosis in the frail patient are: demographic (age over 80 years); lifestyle habits (sedentary lifestyle or physical inactivity); clinical (presence of 2 or more associated comorbidities, use of 3 or more drugs and visual or auditory deficit); functional (difficulty for the development of basic or instrumented activities of daily life); affective (presence of depression or anxiety). Among the factors that favor the frailty of the elderly are described chronic diseases and the existence of comorbidities, this condition means a greater consumption of drugs by this population group [2]. Based on the above, the objective of this study is to determine the association between frailty and risk factors in old adults in Guadalupe, Nuevo Leon.

\section{Materials and Methods}

A comparative cross-sectional study was carried out, in the Family Medicine Unit \#32, of the Instituto Mexicano del Seguro Social (IMSS), located in Guadalupe, Nuevo León; in patients which were selected by a consecutive sampling techniques; that met the following inclusion criteria: age of 60 years or more, any sex, with a diagnosis of a chronic disease, it was not necessary to sign the informed consent due to the fact that only clinical records were reviewed; patients with incomplete information were eliminated. The following data were obtained directly from medical records: age, sex, body mass index, osteoporosis, diabetes mellitus, arterial hypertension and polypharmacy. The procedure for the data collection was as follows: age was calculated in years according to the year of birth, sex was determined by the phenotype characteristics of each individual, chronic diseases (osteoporosis, diabetes mellitus, arterial hypertension) were evaluated according to the presence in the electronic medical record, body mass index was evaluated according to the quetelet index (weight/height ${ }^{2}$ ) and polypharmacy was evaluated according to the number of medications that the patient has prescribed.

The recollected data was integrated into data collection sheets and analyzed using the Epi info version 7.2.2.6 program in Spanish, where we applied descriptive statistics; for qualitative variables, frequencies and percentages were used and for quantitative variables, mean and standard deviation were used. For the bivariate analysis, odd ration was used to determinate risk and the Chi-square test was used in

\begin{tabular}{|c|c|c|c|c|c|c|c|c|}
\hline \multirow[b]{2}{*}{ Variable } & \multirow[b]{2}{*}{ Subtype } & \multicolumn{2}{|c|}{$\begin{array}{c}\text { With } \\
\text { Fragility } \\
\text { Syndrome } \\
\text { (Cases) }\end{array}$} & \multicolumn{2}{|c|}{$\begin{array}{l}\text { Without } \\
\text { Fragility } \\
\text { Syndrome } \\
\text { (Controls) }\end{array}$} & \multirow[b]{2}{*}{ OR } & \multirow[b]{2}{*}{$\begin{array}{c}95 \% \\
\mathrm{Cl}\end{array}$} & \multirow[b]{2}{*}{$\mathrm{P}$} \\
\hline & & $\mathrm{N}$ & $\%$ & $\mathrm{~N}$ & $\%$ & & & \\
\hline \multirow{2}{*}{ Sex } & Men & 69 & 66.3 & 47 & 59.4 & \multirow{2}{*}{1.04} & \multirow{2}{*}{$0.5-1.9$} & \multirow{2}{*}{$>0.05$} \\
\hline & Women & 35 & 33.6 & 25 & 58.3 & & & \\
\hline \multirow{2}{*}{ Osteoporosis } & Yes & 4 & 3.8 & 2 & 66.6 & \multirow{2}{*}{1.4} & \multirow{2}{*}{$0.2-7.9$} & \multirow{2}{*}{$>0.05$} \\
\hline & No & 99 & 96.1 & 70 & 58.5 & & & \\
\hline \multirow{2}{*}{$\begin{array}{l}\text { Diabetes } \\
\text { Mellitus }\end{array}$} & Yes & 42 & 40.7 & 36 & 32.6 & \multirow{2}{*}{0.68} & \multirow{2}{*}{$0.3-1.2$} & \multirow{2}{*}{$>0.05$} \\
\hline & No & 61 & 59.2 & 36 & 62.8 & & & \\
\hline \multirow{2}{*}{$\begin{array}{c}\text { Arterial } \\
\text { Hypertension }\end{array}$} & Yes & 70 & 67.3 & 46 & 60.3 & \multirow{2}{*}{1.1} & \multirow{2}{*}{$0.6-2.1$} & \multirow{2}{*}{$>0.05$} \\
\hline & No & 34 & 32.6 & 26 & 56.6 & & & \\
\hline \multirow{2}{*}{ Polypharmacy } & Yes & 70 & 67.3 & 41 & 63 & \multirow{2}{*}{1.5} & \multirow{2}{*}{$0.8-2.8$} & \multirow{2}{*}{$>0.05$} \\
\hline & No & 34 & 32.6 & 30 & 53.1 & & & \\
\hline
\end{tabular}

N: Frequency; \%: Percentage; >: More than; OR: Odds Ratio; Cl: Confidence Interval; P: Chi Square.

the dichotomous qualitative variables to determinate statistically significant differences between the groups (with fragility syndrome and without fragility syndrome). The Kolmogorov-Smirnoff test was used to establish the normality of the data. It was considered a $\mathrm{p}$ $<0.05$ as statistically significant, with a $95 \%$ confidence interval. The Protocol was authorized by the Local Committee of Research and Ethics in Health Research from the Family Medicine Unit \#32, where this study took place.

\section{Results}

We analyzed a sample of 181 patients obtaining 105 cases (58.01\%) and $76(41.99 \%)$ controls, for the diagnosis of frailty syndrome the criteria of Ensrud were used, a higher frequency of fragility was found in women than in men $(66 \%, n=69$ vs $34 \%, n=36)$. Of the total of participants, the mean age was $68 \pm 7.3(\mathrm{SD})$ and the body mass index mean was $29 \pm 5.5$ (SD). The distribution by categories of the body mass index was as follows (graphic 1): low weight $1.2 \%(\mathrm{n}=2)$; normal weight $16.6 \%(n=27)$; overweight $41.9 \%(n=68)$; obesity grade 1 , $27.1 \%(n=44)$; obesity grade $2,9.2 \%(n=15)$ and obesity grade $3,3.7 \%$ $(\mathrm{n}=6)$.

The following results were obtained from the association between fragility syndrome and associated variables (Table 1): sex (OR 1.04, 95\% CI 0.55-1.97, p >0.05), osteoporosis (OR 1.41, 95\% CI 0.25-7.93, $\mathrm{p}>0.05$ ), diabetes mellitus (OR $0.68,95 \%$ CI 0.35-1.26, $\mathrm{p}>0.05$ ), arterial hypertension (OR 1.16, 95\% CI 0.61-2.18, p >0.05) and polypharmacy (OR 1.5, 95\% CI $0.80-2.8, \mathrm{p}>0.05$ ). None of the associations was statistically significant.

\section{Discussion and Conclusion}

The objective of this investigation was to determine the association of risk factors for the syndrome of fragility; the fragility is defined as a syndrome of physiological deterioration in the old age that is characterized by a marked vulnerability to the adverse results for the health. In this research study, the Ensurd questionnaire was used to detect frailty in patients over 60 years of age in family medicine unit \# 32 of the Instituto Mexicano del Seguro Social. The prevalence in 
Mexico is 39\% and is more frequent in women (45\%) than in men (30\%) [4], which agrees with what was found in our study, where frailty syndrome occurred more frequently in women (66\%) than in men (34\%). Among the medical risk factors for development of frailty are: coronary heart disease, chronic obstructive pulmonary disease, cerebral vascular disease, congestive heart failure, diabetes mellitus, hypertension, arthritis, anemia, depression, smoking, use of hormone replacement therapy, polypharmacy and vitamin D deficiency; in our research we found associations with frailty syndrome finding $\mathrm{OR}>$ 1 for sex, osteoporosis, arterial hypertension and polypharmacy, as well as $\mathrm{OR}<1$ for Diabetes Mellitus, without statistically significant differences.

This is the first time that a study on the frailty syndrome has been carried out in our family medicine unit, so the research will be a reference base for future research, allowing improvement in health education about this topic. We can conclude that although the variables studied did not have a significant association with the frailty syndrome, it is necessary to pay attention on the population aging that will bring consequences related to age. It is also necessary to search and disseminate information on geriatric syndrome to make an early diagnosis, predictive stratification and establish an individualized and timely treatment.

\section{References}

1. Gonzalez KD. Envejecimiento demográfico en México: análisis comparativo entre las entidades federativas. Mexico: CONAPO. pp. 113-129.

2. Diagnóstico y tratamiento del Trastorno Depresivo en el adulto. Guia de practica clínica, México: Secretaría de Salud; 2011.

3. Romero-Cabrera AJ. Fragilidad y enfermedades crónicas en los adultos mayores. Med Int Mex. 2011; 27: 455-462.

4. Martínez-Arroyo JL, Gómez-García A, Sauceda-Martínez D. Prevalencia de la polifarmacia y la prescripción de medicamentos inapropiados en el adulto mayor hospitalizado por enfermedades cardiovasculares. Gac Med Mex. 2014; 150: 29-38

5. Diagnóstico y Tratamiento del Síndrome de Fragilidad en el Adulto Mayor. Guia de practica clínica, México: Secretaría de Salud; 2014.
J Fam Med - Volume 6 Issue 1 - 2019

ISSN : 2380-0658 | www.austinpublishinggroup.com

Ramirez-Leyva et al. (C) All rights are reserved
Citation: Moreno-Sanchez MM, Martínez-Castillo JA, García-Leija DL, Ramirez-Gonzalez JF, Diaz-Alfaro JA and Ramirez-Leyva DH. Chronic Diseases as a Risk Factor for Frailty Syndrome. J Fam Med. 2019; 6(1): 1159. 